\title{
Digital coherent receiver employing photonic downconversion for phase modulated radio-over-fibre links
}

Zibar, Darko; Caballero Jambrina, Antonio; Guerrero Gonzalez, Neil; Schaeffer, Christian; Tafur Monroy, Idelfonso

Published in:

IEEE MTT-S International Microwave Symposium Digest, 2009. MTT '09

Link to article, DOI:

10.1109/MWSYM.2009.5165709

Publication date:

2009

Document Version

Publisher's PDF, also known as Version of record

Link back to DTU Orbit

Citation (APA):

Zibar, D., Caballero Jambrina, A., Guerrero Gonzalez, N., Schaeffer, C., \& Tafur Monroy, I. (2009). Digital coherent receiver employing photonic downconversion for phase modulated radio-over-fibre links. In IEEE MTTS International Microwave Symposium Digest, 2009. MTT'09 (pp. 365-368). IEEE.

https://doi.org/10.1109/MWSYM.2009.5165709

\section{General rights}

Copyright and moral rights for the publications made accessible in the public portal are retained by the authors and/or other copyright owners and it is a condition of accessing publications that users recognise and abide by the legal requirements associated with these rights.

- Users may download and print one copy of any publication from the public portal for the purpose of private study or research.

- You may not further distribute the material or use it for any profit-making activity or commercial gain

- You may freely distribute the URL identifying the publication in the public portal 


\title{
Digital Coherent Receiver Employing Photonic Downconversion for Phase Modulated Radio-over-Fibre Links
}

\author{
Darko Zibar ${ }^{1}$, Antonio Caballero ${ }^{1}$, Neil Guerrero González ${ }^{1}$, Christian G. Schaeffer ${ }^{2}$ and \\ Idelfonso Tafur Monroy ${ }^{1}$ \\ ${ }^{1}$ DTU Fotonik, Department of Photonics Engineering, Technical University of Denmark, Kgs. Lyngby, \\ DK 2800, Denmark \\ dazi@fotonik.dtu.dk \\ ${ }^{2}$ Communications Laboratory, Dresden University of Technology, D-01062 Dresden, Germany, \\ schae@ifn.et.tu-dresden.de
}

\begin{abstract}
A digital coherent receiver employing photonic downconversion is presented and experimentally demonstrated for phase-modulated radio-over-fibre optical links. The receiver is capable of operating at frequencies exceeding the bandwidth of electrical analog-to-digital converter by using photonic downconversion to translate the high-frequency input RF signal to the operating frequency range of the analog-to-digital converter. First, using linear digital demodulation scheme we measure SFDR of the link at microwave frequency of $5 \mathrm{GHz}$. Thereafter, successful signal demodulation of $50 \mathrm{Mbit} / \mathrm{s}$ Binary Phase Shift Keying (BPSK) modulated data signal at 5 GHz RF carrier frequency is experimentally demonstrated by using an analog-to-digital converter with only $1 \mathrm{GHz}$ bandwidth. We successfully demonstrate signal demodulation, using the proposed digital coherent receiver with photonic downconversion, after $40 \mathrm{~km}$ of transmission through standard single mode fiber.
\end{abstract}

Index Terms - microwave photonics, analog links, digital signal processing, digital communication receivers, radio-over-fiber.

\section{INTRODUCTION}

Radio-over-fibre technology is currently receiving large attention due to its ability to provide simple antenna front ends, increased capacity and increased wireless access coverage [1]. Currently, there is most focus on Intensity Modulated (IM) Direct Detection (DD) radio-over-fiber links since they rely on already well established technology and can thereby provide very low cost implementation [2]. However, baseband optical communication is finally moving towards digital signal processing enabled coherent detection thus allowing for advanced modulation formats to be used [3]. Similar trend may follow for radio-over fibre systems. Coherently detected radio-over-fibre systems would enable the information to be carried in both the amplitude and phase or in different states of the polarization of the optical field. Additionally, the selectivity of coherent receiver is very well suited for access networks. Recently, there has been a lot of effort on coherent radio-over-fibre optical links using either analog or digital demodulation techniques [4-8]. Both analog and digital demodulation techniques have their advantages and disadvantages, however, when it comes to flexibility, implementation of different functionalities and impairment compensation, digital demodulation schemes are to be preferred [8]. One of the challenges associated with the digital demodulation techniques are the high sampling rates and bandwidth limitations of Analog-to-Digital (A/D) converters. Bandwidth and dynamic range limitations of $\mathrm{A} / \mathrm{D}$ converters limit the operating range of coherent receivers using digital demodulation techniques up to few $\mathrm{GHz}[9,10]$. One way to extend the frequency range of digital coherent receivers beyond few $\mathrm{GHz}$ is to use photonic downconversion as reported in [9-11] and references therein.

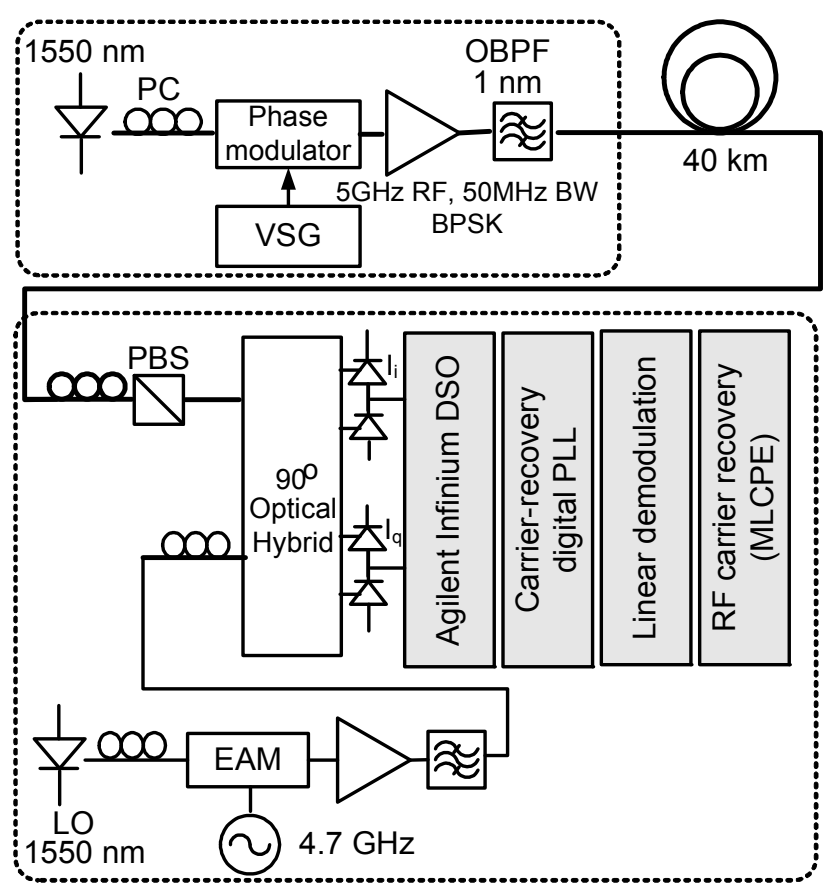

Figure 1. Experimental set-up for the demonstration of digital coherent detection employing photonic downconversion for phase modulated radio-over-fibre signals. VSG: Vector Signal Generator, EAM: Electro-Absorption Modulator.

Using photonic downconversion, the RF signal bandwidth is transferred to an Intermediate Frequency (IF) which falls within the operating range of $\mathrm{A} / \mathrm{D}$ converters. The demonstration of photonic downconversion in combination 
with digital coherent demodulation for phase modulated radioover-fibre links has been reported in [10]. The approach presented in [10] had an emphasis on analog communication with focus on linear signal demodulation. In this paper, we first experimentally evaluate digital linear signal demodulation at $5 \mathrm{GHz}$ in order to compute the dynamic range of the microwave link. Thereafter, photonic downconversion is employed in order to transfer $50 \mathrm{Mbit} / \mathrm{s}$ BPSK signal at $5 \mathrm{GHz}$ $\mathrm{RF}$ carrier frequency down to $300 \mathrm{MHz}$ intermediate frequency which then falls within the frequency range of $A / D$ converter $(1 \mathrm{GHz})$. We report on successful signal demodulation and data recovery for back-to-back and after $40 \mathrm{~km}$ of Single Mode Fibre (SMF) transmission, using digital coherent detection. Additionally, we present numerical simulations for a comparison between feed-forward and feedback RF carrier phase estimation schemes.

\section{EXPERIMENTAL SET-UP}

The experimental set-up for a phase modulated radio-overfibre optical link employing photonic downconversion is shown in Figure 1. The transmitter consists of a DFB laser with $\sim 2 \mathrm{MHz}$ linewidth and wavelength in the range of $1550 \mathrm{~nm}$. The output of the transmitter laser is amplified by a conventional EDFA, optically band-pass filtered and coupled to the optical phase modulator. A Vector Signal Generator (VSG) is used to generate an RF carrier $\left(\mathrm{F}_{\mathrm{RF}}=5 \mathrm{GHz}\right)$ which is modulated by $50 \mathrm{Mbit} / \mathrm{s}$ BPSK data signal. Square root raised cosine filtering with a roll-off factor, $\alpha=0.5$, is applied for pulse shaping to the digital data stream. The RF data signal is then used to drive a conventional lithium-niobate optical phase modulator. The phase modulated optical data signal is sent through $40 \mathrm{~km}$ of SMF and split in two polarizations using a Polarization Beam Splitter (PBS). Only one polarization is sent to the receiver. At the receiver, a $90^{\circ}$ optical hybrid is used to mix the received data signal with the pulsed Local Oscillator (LO) laser signal. The in-phase $\left(\mathrm{I}_{\mathrm{i}}\right)$ and quadrature $\left(\mathrm{I}_{\mathrm{q}}\right)$ optical signal components are detected with two pairs of balanced photodiodes with $7.5 \mathrm{GHz} 3 \mathrm{~dB}$ bandwidth.

For photonic downconversion, we use a pulsed optical LO as shown in Figure 1. The pulsed LO is generated by gating light from a LO Continuous Wave (CW) laser source by applying a sinusoidal RF signal to an Electro-Absorption Modulator (EAM). The wavelength of the LO CW laser source is set to $1550 \mathrm{~nm}$ and tuned to match the transmitter wavelength. The peak power of the pulsed LO is after amplification and filtering approximately $-6 \mathrm{dBm}$. The linewidth of the LO CW light source is $\sim 3 \mathrm{MHz}$. The frequency of the applied RF signal is $F_{L O}=4.7 \mathrm{GHz}$, the RF power is $12 \mathrm{dBm}$ and the bias voltage applied to EAM is approximately $1.98 \mathrm{~V}$ in order to obtain the highest extinction ratio of the pulses. The generated optical pulses at the repetition rate of $4.7 \mathrm{GHz}$ are subsequently amplified by an EDFA and thereafter filtered in order to remove amplified spontaneous emission noise which lies outside the signal bandwidth. The generated pulse width is approximately $40 \mathrm{ps}$, corresponding to $18 \%$ duty cycle. Due to the mixing process in the photodiodes, the original data signal at $5 \mathrm{GHz} \mathrm{RF}$ carrier frequency with $50 \mathrm{Mb} / \mathrm{s}$ BPSK data modulation will be downconverted to an IF frequency: $\mathrm{F}_{\mathrm{IF}}=\left|\mathrm{F}_{\mathrm{RF}}-\mathrm{F}_{\mathrm{LO}}\right|=300 \mathrm{MHz}$. The detected photocurrents are then digitized using a real time oscilloscope with $1 \mathrm{GHz}$ analog bandwidth at 40 Gsamples/s. The sampled photocurrent is later used for offline signal demodulation and data recovery. The frequency difference between the transmitter and LO laser is measured to be in the range between $20 \mathrm{MHz}$ and $400 \mathrm{MHz}$. The post-processing of the digitized data consists of carrierrecovery digital Phase-Locked Loop (PLL), linear signal demodulation, residual frequency estimation unit, RF carrier phase recovery and matched filtering (see [8] for more details). The carrier-recovery digital PLL is used to remove optical frequency and phase difference between transmitter and LO laser.

\section{SFDR MEASUREMENTS}

In this section, we investigate linearity of our microwave link, at $5 \mathrm{GHz}$, using the digital coherent receiver shown in Figure 1. For the linearity measurements, the coherent receiver is operated in CW mode, i.e. LO is not pulsed. The linearity of a RF system is characterized by Spurious Free Dynamic Range (SFDR). For the SFDR measurement, the two RF signals are generated with two independent RF generators, at $5 \mathrm{GHz}$ and $5.01 \mathrm{GHz}$, respectively. The two RF paths are isolated to ensure that any spurious intermodulation products are suppressed by $>70 \mathrm{~dB}$. The two RF tones are then used to drive an optical phase modulator and coherently detected using $90^{\circ}$ optical hybrid. The received signal is then digitized at 40 Gsamples/s, and offline processed by applying carrier recovery digital PLL and linear demodulation scheme.

In Figure 2, the fundamental and third order intermodulation products are plotted as a function of the input RF signal power. The noise level is determined from the minimum distinguishable TOD product, leading to $-46 \mathrm{dBm}$ in a resolution bandwidth of $20 \mathrm{kHz}$. The system shows high linearity, achieving $87 \mathrm{~dB} \cdot \mathrm{Hz}^{2 / 3}$ of SFDR, with a Third Order Intercept (IP3) of $52 \mathrm{dBm}$.

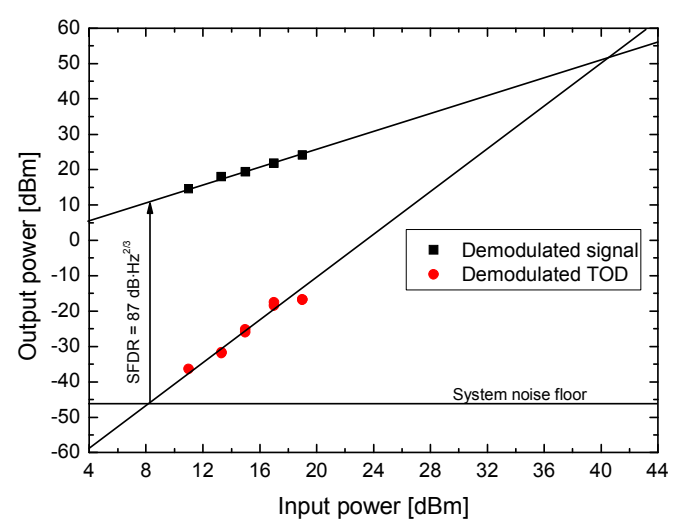

Figure 2. Fundamental and third order intermodulation product as a function of input RF signal power. Resolution bandwidth is $20 \mathrm{kHz}$. 


\section{SIMULATION RESULTS FOR RECEPTION SCHEMES}

In this section, we also carry out simulations without photonic downconversion in order to test the whole digital demodulation unit and also to test two different types of RF carrier phase recovery algorithms. We have implemented feedback and feed-forward RF carrier phase recovery algorithms based on Maximum Likelihood Estimation [8]. For the simulations we used $10 \mathrm{GHz}$ RF carrier frequency with $1.25 \mathrm{~Gb} / \mathrm{s}$ BPSK modulated data.

The disadvantage of the feedback approach is that it is sensitive to the delay in the feedback path. Also, the phase estimation interval of the feed-forward RF carrier phase recovery is restricted to $\pi / 2$ for BPSK data signal modulation format. Additionally, feed-forward maximum likelihood based approach requires higher sampling rate since the signal is lifted to the power of 2 in order to remove BPSK data signal modulation. In Figure 3, the Bit-Error-Rate (BER) is computed as a function of the photodetected signal SNR using feed-forward and feedback RF carrier phase algorithms. It is observed in Figure 2, that the feed-forward RF carrier phase algorithm outperforms the feedback algorithm by approximately $1.5 \mathrm{~dB}$ for a BER of $10^{-4}$

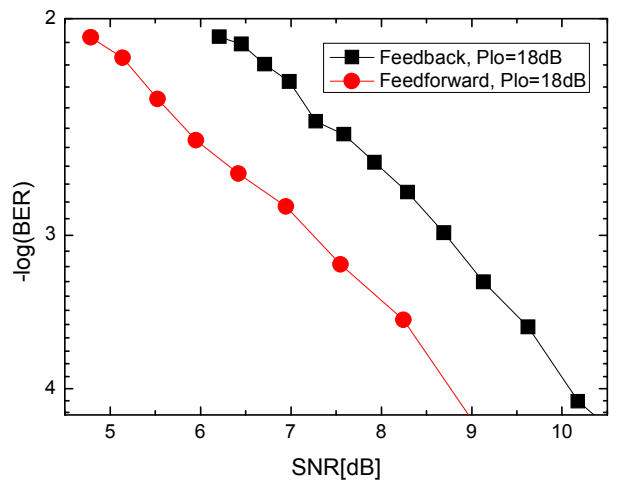

Figure 3. Simulation results for bit-error-rate as a function of the signal-to-noise ratio of the photodetected photocurrent for feedback and feed-forward RF carrier phase recovery.

\section{EXPERIMENTAL RESULTS - PHOTONIC DOWNCONVERSION}

In Figure 4, the measured spectrum of the downconverted and sampled photocurrent is plotted before and after carrierrecovery digital phase-locked loop. The parameters for the experimental set-up are as described in section II. It is observed that the frequency off-set between the transmitter and pulsed LO laser is approximately $30 \mathrm{MHz}$. After applying the carrier-recovery digital PLL, the frequency off-set is removed.

It can be observed from Figure 4, that the data signal is now clearly centered around $\mathrm{F}_{\mathrm{IF}}=300 \mathrm{MHz}$ which correspond to the frequency difference between the repetition rate of the pulsed LO source and input RF carrier frequency. In Figure 4, the biterror-rate of the downconvereted and demodulated $50 \mathrm{Mbit} / \mathrm{s}$ BPSK data signal is plotted as a function of input data signal Optical Signal to Noise Ratio (OSNR) for back-to-back case and after $40 \mathrm{~km}$ of transmission through standard single mode fibre. The data signal recovery is achieved by using the digital receiver in Figure 1. For the BER computation, we have considered 10000 bits. BER below $10^{-3}$ is achieved, for backto-back (B2B) and after $40 \mathrm{~km}$ of transmission, at which forward error correction can be used to maintain the transmission quality. However, after $40 \mathrm{~km}$ of fiber transmission a penalty of about $2 \mathrm{~dB}$ is observed, as shown in figure 5. We stress that we did not use any equalization algorithm which could potentially improve the signal transmission by reducing the amount of intersymbol interference. Additionally, the drift in the system may have caused the discrepancy between back-to-back curve and biterror-rate curve measured after $40 \mathrm{~km}$ fiber transmission.

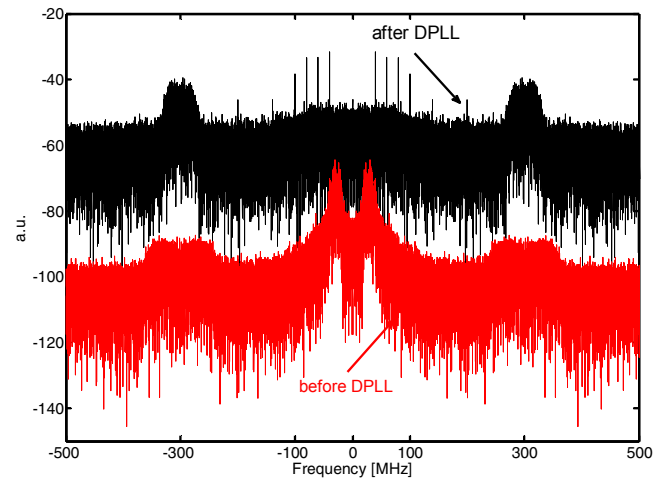

Figure 4. Frequency spectra of the downconverted and sampled photocurrent before and after carrier-recovery digital PLL.

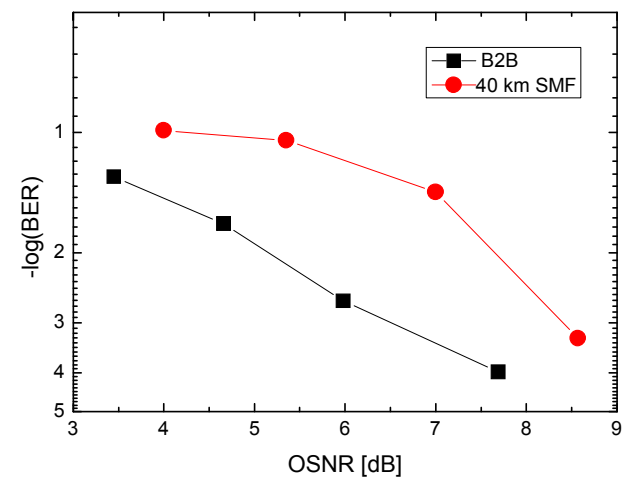

Figure 5. Bit-error-rate as a function of the OSNR of the input data signal for the back-to-back and after $40 \mathrm{~km}$ of transmission. The OSNR is measured in $0.1 \mathrm{~nm}$ bandwidth

\section{CONCLUSION}

In this paper, we have demonstrated digital coherent detection assisted by photonic downconversion for phase-modulated radio-over-fibre optical links. First we have demonstrated a SFDR of $87 \mathrm{~dB} \cdot \mathrm{Hz}^{2 / 3}$ for the proposed system. Photonic downconversion of $50 \mathrm{Mbit} / \mathrm{s}$ BPSK modulated data signal at $5 \mathrm{GHz}$ RF carrier frequency down to $300 \mathrm{MHz}$ IF and subsequent digital signal demodulation has been experimentally demonstrated, being the first measurements 
performed at microwave frequencies. A penalty of approximately $2 \mathrm{~dB}$ is observed after $40 \mathrm{~km}$ of transmission through standard single mode fibre compared to back-to-back case, without using any post-equalization algorithms. We have thus demonstrated that digital coherent detection assisted with photonic downconversion can be used for radio-over-fibre links operating at frequencies exceeding the bandwidth of $A / D$ converters.

\section{REFERENCES}

[1] J. Capmany and D. Novak, "Microwave Photonics Combines two Worlds," Nature Photonics, vol. 1, pp. 319-330, June 2007

[2] C.H. Cox III, E. I. Ackerman, G. E. Betts and J. L. Prince, "Limits on the Performance of RF-Over-Fiber Links and Their Impact on Device Design," IEEE Transactions on Microwave Theory and Tech., vol. 54, no. 2, pp. 906-920, Feb. 2006.

[3] T. Pfau, S. Hoffmann. O. Adamtzyk, R. Peveling, V. Herath, M. Pormann and R. Noe, "Coherent optical communication: Towards real time systems at $40 \mathrm{~Gb} / \mathrm{s}$ and beyond," Optics Express, vol. 16, no. 2, pp. 866 - 872, January 2008

[4] T. R. Clark and M. L. Dennis, "Coherent optical phase modulation link", IEEE Photonic Technology Letters, vol. 19, no. 16, August 2007

[5] H. F. Chou, A. Ramaswamy, D. Zibar, L. A. Johansson, J. E. Bowers, M. Rodwell and L. A. Coldren, "High-Linearity Coherent Receiver with Feedback", IEEE Photonic Technology Letters, vol. 19, no. 12, pp. 940-942, June 2007

[6] Y. Li, D. Yoo, P. Herczfeld, A. Rosen, A. Madjar, and S. Goldwasser, "Receiver for coherent fiber-optic link with high dynamic range and low noise figure," in Proceedings of Topical Meeting on Microwave Photonics, Seoul, South Korea, paper TP-39, 2005

[7] D.Zibar, L. A. Johansson, H.-F. Chou, A. Ramaswamy, M. Rodwell and J. E. Bowers, "Phase-locked coherent demodulator with feedback and sampling for optically phase modulated microwave links" Journal of Lightwave Technology, vol. 26, no. 15, pp. 2460-2475, January 2008

[8] D. Zibar, y. Xu, C. Peucheret, P. Jeppesen and I. Tafur Monroy, "'Digital coherent receiver for phase-modulated radio-over-fibre optical links". Photonic Technology Letters, vol. 21, no. 3, 2009

[9] M. Park, J.-W. Kim, F. Kaertner and M. Perrott, "An optical electrical sub-sampling receiver employing continues-time $\Delta \Sigma$ modulation," in Proceedings of European Solid State Circuits Conference, pp. $182-185,2006$

[10] T. R. Clark and M. L. Dennis, "Photonics downconversion and linearization of an X-band fiber optic link using optical I/Q modulation," in Proceedings of Conference on Laser Electro Optics (CLEO) 2006, Baltimore, Maryland, USA, paper CTuAA2, 2006
[11] A. Ramaswamy, L. A. Johansson, J. Klamkin, D. Zibar, L A. Coldren, M. Rodwell and J. E. Bowers, "Optical phase demodulation of a $10 \mathrm{GHz}$ RF signal using optical sampling," in Proceedings of Conference on Coherent Optical Technologies (COTA), Boston, MA, USA, 2008 